Itinerarios culturales y rutas turístico-culturales 10

\title{
¿Por qué no funcionan turísticamente algunos itinerarios o rutas culturales?
}

Juan Ignacio Pulido Fernández. Profesor de Economía A plicada. Universidad de Jaén. Secretario General de la Asociación Española de Expertos Científicos en Turismo (AECIT)

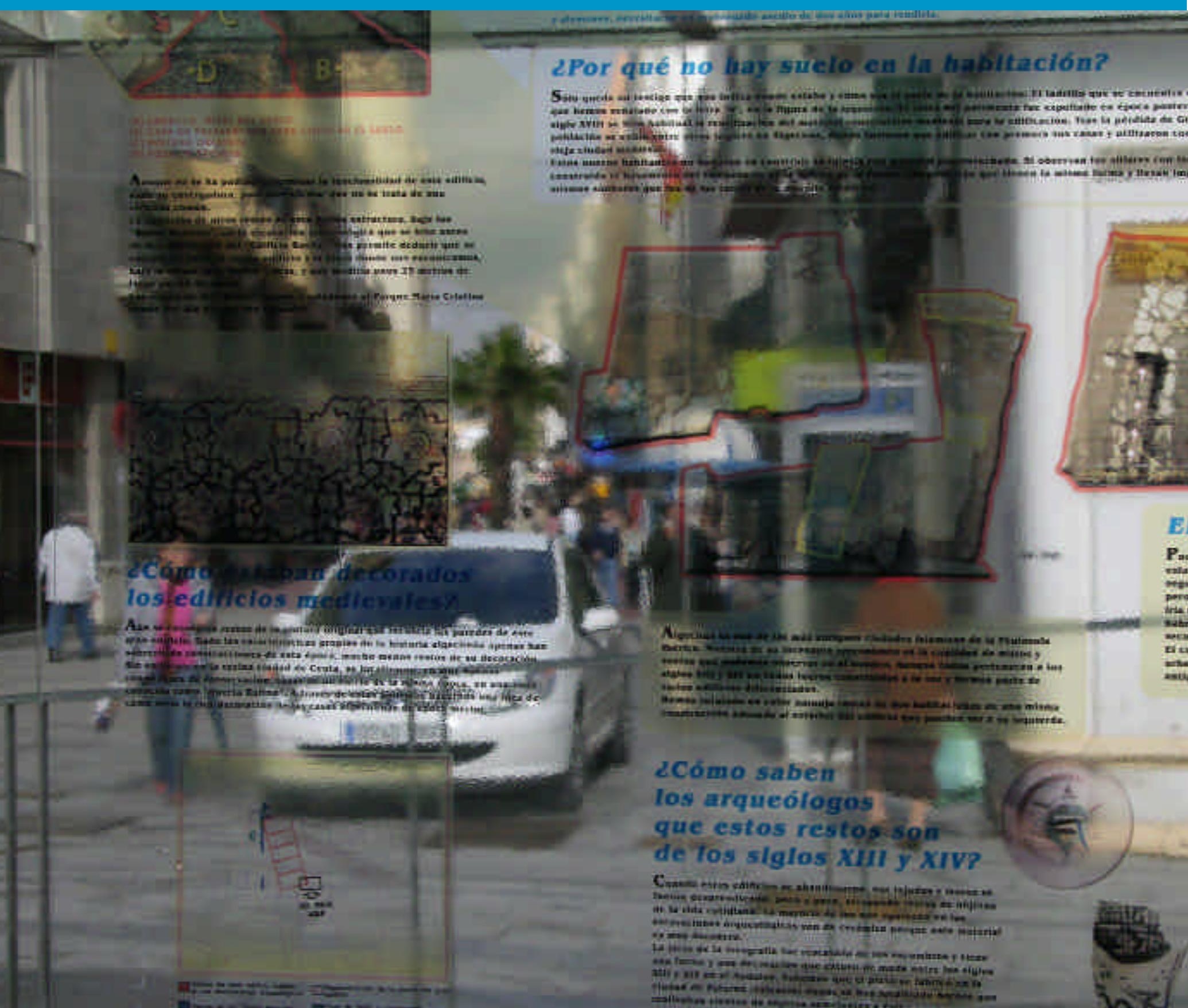


Los itinerarios o rutas culturales agrupan lugares, monumentos, museos $y$, en general, recursos del patrimonio cultural con un denominador común (territorial, temático, una tipología determinada de patrimonio, un personaje, etc.). Su creación promueve la cooperación, abarata la gestión, permite una promoción e información unificadas y un mejor acceso a los mercados. Son también un buen pretexto para impulsar mecanismos de intervención sobre el territorio: construcción de carreteras y equipamientos, mejora del transporte, recuperación del patrimonio, limpieza y adecuación de áreas urbanas degradadas, señalización, etc. Sin embargo, un it inerario, o una ruta, cultural no se convierte automáticamente en un itinerario turístico, puesto que, para ello, debe contar con un conjunto de elementos, en lo cultural y en lo turístico, que hagan la ruta realizable, atractiva y, en consecuencia, comercializable.

En muchos casos, aunque pueda existir un patrimonio cultural valioso, hay poca infraestructura turística (alojamiento, restauración) que permita rentabilizar el atractivo cultural del lugar. Esto sucedió, por ejemplo, con muchos de los itinerarios propuestos en sus inicios por el Legado Andalusí, de gran interés histórico y cultural, pero que adolecían de una of erta turística básica de similar calidad a la del producto cultural propuesto, que se ha ido conformando posteriormente.

En otros casos, el problema es de carácter operativo, al haber diseñado la ruta incluyendo elementos patrimoniales de difícil, incluso imposible, acceso, aunque sólo sea en determinadas épocas, o en momentos puntuales. Es recomendable, para evitar estos inconvenientes, que las rutas se puedan segmentar en itinerarios alternativos y complementarios, con entidad suficiente cada uno, que permitan organizar los viajes de forma variable.
También suele ser muy habitual organizar estos itinerarios o rutas con una visión exclusivamente de oferta, cuando el turismo es una actividad condicionada de forma determinante por el lado de la demanda. Dicho de otro modo, el diseño de la ruta suele hacerse teniendo en cuenta los intereses, necesidades y expectativas de quienes gestionan la oferta, pero pocas veces se analizan las motivaciones 0 intereses de los turistas. El resultado final es brillante en su configuración intelectual pero un auténtico desastre comercial, pues no responde al cuadro motivacional básico de este tipo de demanda.

Por otra parte, a menudo, suele haber demasiada acción publicitaria en relación con la oferta real, constatándose que muchos destinos invierten más en promoción (lo más fácil de hacer) que en crear y comercializar el producto, o mejorar la calidad de la of erta. Una verdadera promoción debe apoyar un producto perfectamente comercializable, con una información complementaria, disponible en tiempo real, completamente actualizada. Tanto por el tipo de demanda como por los mercados en los que se comercializa el turismo cultural, la promoción tiene que ser muy selectiva, primando los conteni dos informativos sobre los de imagen, es decir, lo contrario de lo que se ha venido haciendo en una gran parte de las actuaciones llevadas a cabo en España.

Finalmente, otro de los errores más habituales es considerar que un itinerario o ruta turístico cultural es una oferta estática, permanente y constante, que no requiere de una gestión activa. En general, la gestión del turismo cultural no puede basarse sólo en lo ya existente, en la mera puesta en valor del legado cultural, sino que debe renovarse, tener un dinamismo propio. Es necesario que exista una capacidad de innovar, de crear una of erta turístico-cultural diferencial, atractiva y dinámica. No puede, en cualquier caso, negarse que en España se ha avanzado mucho en este sentido en los últimos años. 


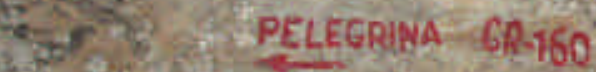
CANIMOQEL CID.

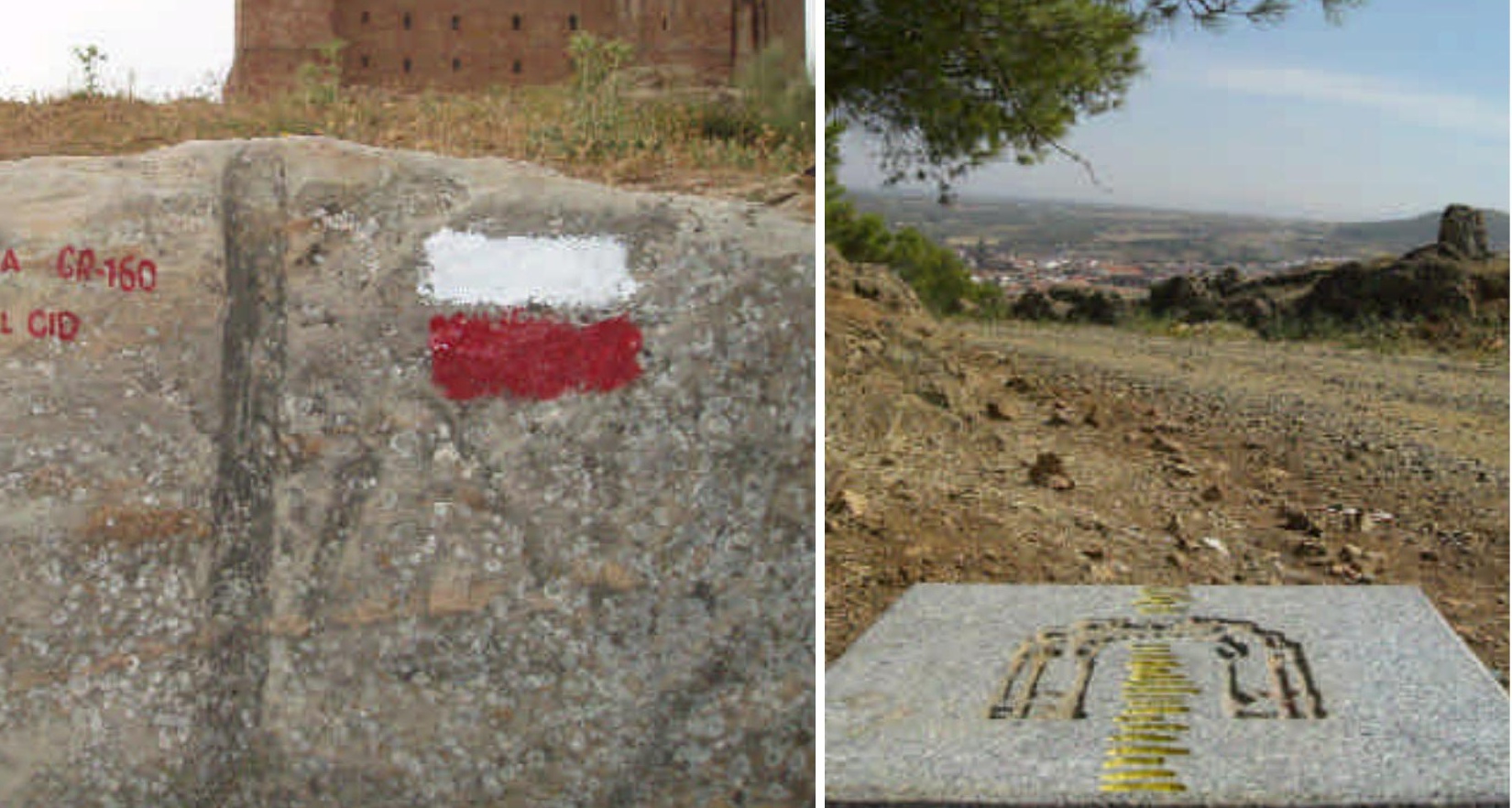

\section{sisesis}
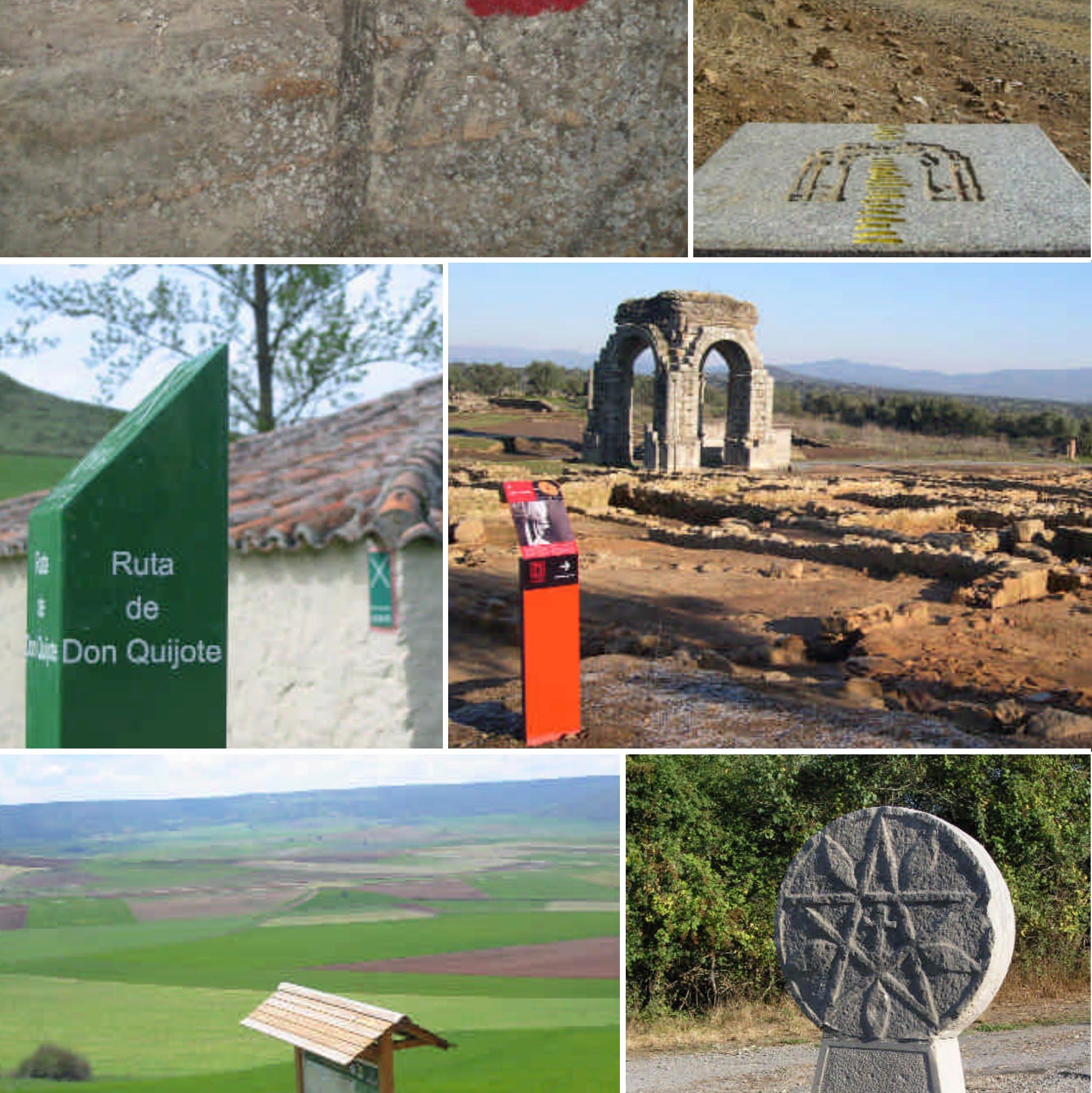

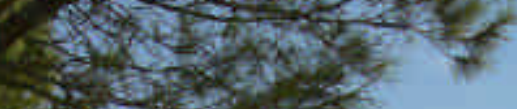
$x=10$ s.

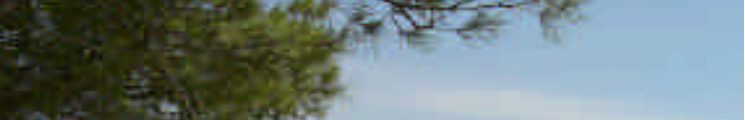


S Señalización provisional del Camino del Cid en Guadalajara, tramo inscrito como Sendero de Gran Recorrido de acuerdo con los criterios del proyecto actual de homologación señalética de la ruta / Consorcio Camino del Cid

S Poste de señalización de la ruta Vía de la Plata en Extremadura, a su paso por la localidad Los Santos de Maimona (Badajoz) / Isabel Cú́lLAR

Q Señal informativa indicativa de la Ruta de Don Quijote / Empresa Pública Don Quijote de la Mancha 2005, S.A.

Q El tetrapylon, en los yacimientos de la ciudad romana de Cáparra (Cáceres), está situado en plena Vía de la Plata / Oficina de Gestión DE Alba Plata, Consejería de Cultura de la Junta de Extremadura

U Panel informativo de la Ruta de Don Quijote con mapas, una relación de recursos disponibles en la zona y datos de contacto / Empresa Pública Don Quijote de la Mancha 2005, S.A.

U Estela de piedra situada en la población de Ostabat; con símbolos peregrinos como la vieira o concha, indica el lugar donde convergen las principales rutas del Camino de Santiago / José Manuel SAntos Madrid

Errores más frecuentes en la configuración de itinerarios 0 rutas culturales como productos turísticos

j La ruta es un diseño intelectual, pero no existe como producto o servicio turístico. Existe como "idea" en los folletos de promoción turística, pero no está en venta como producto en agencias de viajes o centrales de reservas.

j No hay garantía de acceso a los recursos (monumentos cerrados, llaves en paradero desconocido, aplicación discrecional de la apertura de los monumentos o admisión de visitantes, limitaciones numéricas de acceso...), lo que no permite garantizar las operaciones turísticas.

j Ausencia, o deficiencia, de señalización, que dificulta los recorridos auto-guiados.

j Se cuenta con poca información sobre la ruta, o dicha información es mayoritariamente genérica, tópica, indiscriminada. No existe información interpretativa, ni selectiva.

j Existen grandes diferencias en las prestaciones de la oferta básica entre distintos puntos o etapas de la misma ruta, dificultando la percepción por parte del turista de un producto homogéneo, uniforme.

j Se cuenta con grandes diferencias, imprevisibles y casua les, en las prestaciones complementarias: guías de turismo, disponibilidad de información turística, etc.

j La oferta de la ruta varía según la estacionalidad: precisamente, en las temporadas bajas, cuando se pretende atraer clientes que desestacionalicen la actividad turística, la oferta de recursos visitables, atractivos y variedad de oferta puede ser menor. j La ruta está más orientada a rentabilizarse por medio de la venta de productos en tiendas que por medio de la calidad de las prestaciones turísticas de la propia ruta.

j En rutas que abarcan diferentes entes territoriales, la señalización varía de tamaño, forma, concepto, frecuencia y disposición durante una misma ruta (Vía de la Plata, Camino de Santiago...).

j Carencia de verdaderos intérpretes del patrimonio cultural que hagan del viaje una experiencia única, atractiva y participativa.

Elementos básicos para la configuración de rutas 0 itinerarios turísticos culturales

j Establecimiento de un eje temático, o hecho diferencial, claramente identificable por el público objetivo.

j Catalogación de puntos y elementos de mayor atractivo a partir de los recursos identificados en el inventario.

j Dosificación de los atractivos, alternando puntos de mayor y menor interés.

j Atención a diferentes motivaciones en la demanda.

j Señalización clara, unificada, interpretativa, durable y accesible a distintos tipos de público.

j Posibilidad de ser rentabilizada como producto o servicio turístico.

j Cierto consenso entre las entidades u organismos que regulan el acceso a los recursos. j. Disponibilidad de personal de contacto bien capacitado en el área de influencia de la ruta.

¿Qué características debe tener la ruta turística cultural ideal?

j Se adapta a las variables funcionales de su demanda objetiva.

j Alimenta las diferentes motivaciones de su demanda objetiva, individual o en grupo.

j Genera una experiencia emocional de alta intensidad. j Incorpora un ocio creativo, ameno, enriquecedor, participativo.

j Permite disponer de alternativas: a inclemencias climatológicas, a inaccesibilidad de determinados recursos.

j Tiene una imagen atractiva y fácil de recordar.

j Está prevista tanto para grupos organizados en origen más homogéneos- como para grupos organizados en destino.

j Garantiza la respuesta a leves variaciones estacionales en sus prestaciones.

j Cuando está configurada como producto turístico, garantiza su operatividad a partir de unos mínimos de usuarios que el público objetivo conoce.

j Se puede contratar, comenzar y abandonar en diversos puntos clave de la propia ruta.

j Ofrece senvicios espeć́ficos para viajeros individuales y en grupos pequeños de alta rentabilidad. 